\title{
Arousal modulates auditory attention and awareness: insights from sleep, sedation, and disorders of consciousness
}

\author{
Srivas Chennu ${ }^{1}{ }^{*}$ and Tristan A. Bekinschtein ${ }^{2}$ \\ Department of Clinical Neurosciences, University of Cambridge, Cambridge, UK \\ ${ }^{2}$ Cognition and Brain Sciences Unit, Medical Research Council, Cambridge, UK
}

\section{Edited by:}

Naotsugu Tsuchiya, Monash

University, Australia

\section{Reviewed by:}

Melanie Boly, Belgian National Fund

for Scientific Research, USA

Boris Kotchouzbey, University of

Tübingen, Germany

\section{*Correspondence:}

Srivas Chennu, Department of Clinical Neurosciences, University of

Cambridge, Herchel Smith Building,

Forvie Site, Robinson Way,

Cambridge CB2 OSZ, UK.

e-mail: sc672@cam.ac.uk
The interplay between attention and consciousness is frequently tested in altered states of consciousness, including transitions between stages of sleep and sedation, and in pathological disorders of consciousness (DoC; the vegetative and minimally conscious states; VS and MCS). One of the most widely used tasks to assess cognitive processing in this context is the auditory oddball paradigm, where an infrequent change in a sequence of sounds elicits, in awake subjects, a characteristic EEG event-related potential called the mismatch negativity, followed by the classic P300 wave. The latter is further separable into the slightly earlier, anterior P3a and the later, posterior P3b, thought to be linked to task-irrelevant "bottom-up" and task-oriented "top-down" attention, respectively. We discuss here the putative dissociations between attention and awareness in DoC, sedation and sleep, bearing in mind the recently emerging evidence from healthy volunteers and patients. These findings highlight the neurophysiological and cognitive parallels (and differences) across these three distinct variations in levels of consciousness, and inform the theoretical framework for interpreting the role of attention therein.

Keywords: attention and awareness, arousal, mismatch negativity, P300, disorders of consciousness, sleep, sedation

\section{INTRODUCTION}

In the study of auditory attention and awareness using electrophysiology, there is a rich body of scientific literature on the mismatch negativity (MMN) and the P300 components observed in the event-related potential (ERP). They are widely regarded as markers of key stages in the information processing hierarchy leading up to conscious perception. The first neural signature the MMN - is a frontocentral negative deflection in the ERP (see Figure 1A), peaking at around $120-220 \mathrm{~ms}$ after the presentation of an "oddball" deviant auditory stimulus embedded within a stream of standard auditory stimuli (Näätänen, 1992). The MMN is often depicted as a difference wave computed by subtracting out the response to the standard stimuli from the deviant stimuli (Sams et al., 1985). In its traditional definition, it is seen as a correlate of the triggering of automatic pre-attentional "reorienting" to the deviant (Näätänen et al., 1978; Näätänen and Michie, 1979; Näätänen, 1990; Alain et al., 1994), though it is known to be modulated by attention (Alain and Woods, 1997; Woldorff et al., 1998; Näätanen et al., 2007) and might be influenced by recurrent feedback activation from frontal areas (Garrido et al., 2007, 2009).

Since the original reports of the MMN (Näätänen et al., 1978) there has been a significant amount of experimental work probing modulations of the MMN in a variety of settings (see Näätanen et al., 2007 for a review). The general conceptual picture that has emerged suggests that the MMN in fact reflects changes in a continually updated context-sensitive auditory memory trace (Winkler et al., 1996; Sussman and Winkler, 2001). One of the main reasons for the sustained empirical interest in the MMN is that it provides researchers access to pre-conscious processing of temporal structure in auditory information beyond the basic sensory stage, but before it benefits from the spotlight of attention or enters conscious perception. Crucially, because of this property, researchers have found the MMN to be valuable in a clinical setting, to probe the abnormalities in auditory processing resulting from neurological dysfunction, and also to track the process of recovery therefrom (Wijnen et al., 2007). Alongside, evidence from sleep and sedation has shown that under certain conditions, the MMN can also be elicited in these states of behavioral unconsciousness (Atienza et al., 2002; Koelsch et al., 2006).

The P300 ERP component is the most widely studied EEG evoked potential signature in cognitive electrophysiology. The evidence in this regard commonly identifies it as positive deflection peak approximately $250-400 \mathrm{~ms}$ post-target, serving as a marker of conscious perception of salient events or stimuli (Sutton et al., 1965, 1967). Depending on the experimental context, it is also seen to be associated with target stimulus consolidation and working memory updating (see Donchin, 1981; Donchin and Coles, 1988; but also see Verleger, 1988). The P300 can often be considered to include two distinct subcomponents, the P3a and the P3b (see Figure 1B). The frontally centered P3a (usually peaking at 250 $300 \mathrm{~ms}$ ) is known to be elicited in a "bottom-up" manner, by novel, unpredictable stimuli, even if they are irrelevant to the task being performed (Courchesne et al., 1975; Squires et al., 1975). Though 


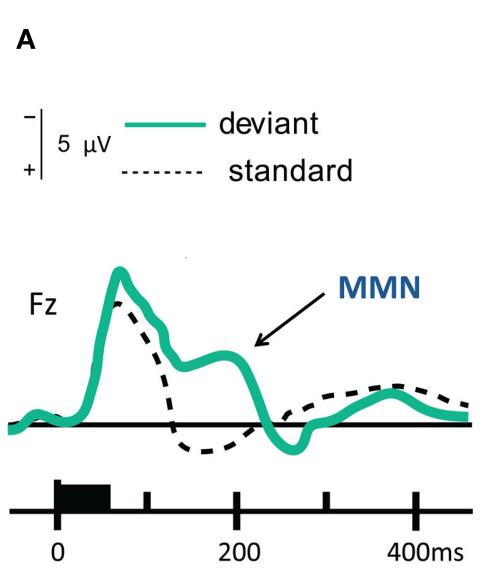

FIGURE 1 | Mismatch negativity (MMN) and P300 in healthy awake adults. (A) MMN evoked by $1032 \mathrm{~Hz}$ deviant tones (20\% probability), when compared to $1000 \mathrm{~Hz}$ standard tones. Adapted from Sams et al. (1985). (B)

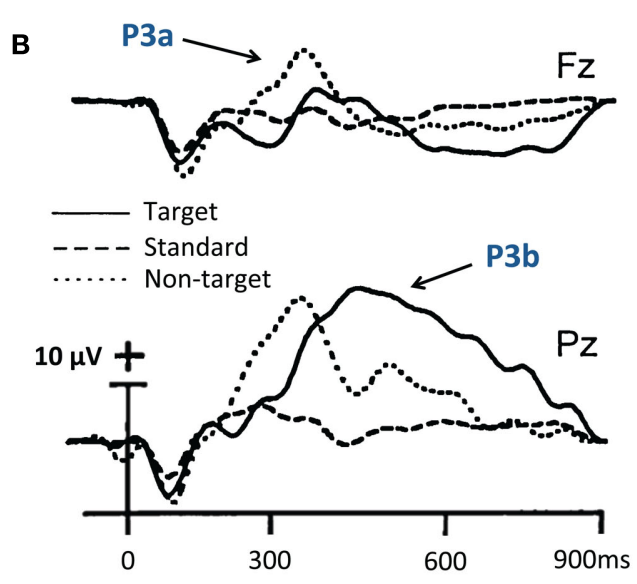

P3a and P3b evoked by $500 \mathrm{~Hz}$ non-target and $2000 \mathrm{~Hz}$ target tones (each with $10 \%$ probability), presented amongst $1940 \mathrm{~Hz}$ standard tones. Adapted from Comerchero and Polich (1999). in many ways the $\mathrm{P} 3 \mathrm{a}$ is related to the MMN, it is considered to index a distinct attention-driven process of stimulus evaluation. In this sense, it can be seen as a correlate of the process that accompanies the reorienting of involuntary attention, having been triggered by processes indexed by the MMN (Schröger, 1996; Escera et al., 2001; Ranganath and Rainer, 2003).

In contrast to the $\mathrm{P} 3 \mathrm{a}$, the more posterior, later $\mathrm{P} 3 \mathrm{~b}$ (peaking at around 300-350 ms) is thought to index the "top-down" deployment of selective attention to stimuli deemed as task-relevant, and their subsequent entry to conscious awareness and working memory (Kok, 2001; Polich and Criado, 2006). Like the MMN, these ERPs have been found to convey valuable information in a clinical setting, leading to applications that have informed a variety of applied questions regarding the nature of perceptual processing in impaired brains (Polich and Herbst, 2000; Polich, 2004; Duncan et al., 2009).

In this review, we highlight findings in the literature that discuss the role of the MMN, P3a and P3b in furthering our understanding of the interplay of attention and consciousness at varying levels of arousal and wakefulness. Importantly, we discuss results from studies involving patients in disorders of consciousness (DoC), a collective term commonly applied to the vegetative and minimally conscious states (VS and MCS, respectively). These studies have tried to connect these ERP components observed in patients to their diagnosis and prognosis. Historically, rates of misdiagnosis amongst patients in the vegetative state, conventionally based on purely behavioral metrics, have been disturbingly high (Schnakers et al., 2009). Given that the MMN and P300 ERPs can be evoked with auditory stimulation reasonably easily, and with relatively short passive experiments, they were the first to be applied in DoC research, with the aim of improving diagnosis and prognosis. In conjunction, we discuss MMN and P300 findings relating to attention and consciousness in the context of sleep and sedation, addressing the longstanding questions regarding the level of processing attainable with volunteers considered to be in non-pathological unconscious states.

\section{THE MMN AND P3a IN DISORDERS OF CONSCIOUSNESS}

Over the last decade, there have been many cohort studies of the prevalence of the MMN and P300 ERPs in patients diagnosed as being in VS and MCS states. Similar in design to studies involving comatose patients (see Daltrozzo et al., 2007 for a meta-analysis), the experimental paradigms in this context have typically used auditory deviant/oddball stimuli, ranging from simple tones to complex stimuli like the patient's own name to evoke the MMN (Figure 2A) and/or P3a (Figure 2B) in DoC (Rappaport et al., 1991; Marosi et al., 1993; Witzke and Schönle, 1996; Lew et al., 1999, 2003; Jones et al., 2000; Kotchoubey et al., 2001, 2005; Kotchoubey, 2005a; Perrin et al., 2006; Wijnen et al., 2007; Qin et al., 2008; Fischer et al., 2010; Cavinato et al., 2011) Indeed, some of these studies report evidence of relatively late, parietally (in electrode space) focused P300 responses in some patients, suggestive of some level of awareness of the deviant stimuli. Furthermore, some of these studies have also demonstrated a convincing link between the detection of these ERPs and a positive prognosis for the patient (Lew et al., 2003; Kotchoubey et al., 2005; Wijnen et al., 2007).

This pattern raises interesting questions about the interrelationship between the neural processes generating these ERPs and how they feed into conscious awareness. More specifically, the temporally predictive link between the MMN/P3a and eventual recovery of consciousness highlights some key aspects of the relationship between attention and awareness in coma and DoC. Firstly, and mostly obviously, the deeper processing of deviants that elicits the $\mathrm{MMN} / \mathrm{P} 3 \mathrm{a}$ is distinct from, and may not necessarily result in conscious awareness of the stimuli. In normal volunteers, a functionally equivalent experimental outcome is usually constructed by setting up another distracting, attentionally demanding task while the subject listens to streams of auditory stimuli with deviants. In such cases, though clear MMNs/P3a ERPs might be elicited, the subject usually does not have a rich conscious awareness of the deviants (Müller et al., 2002; Muller-Gass et al., 2007). Hence, the relative automaticity with which these ERPs can be evoked in volunteers implies that the presence of $\mathrm{MMN} / \mathrm{P} 3 \mathrm{a}$ in 

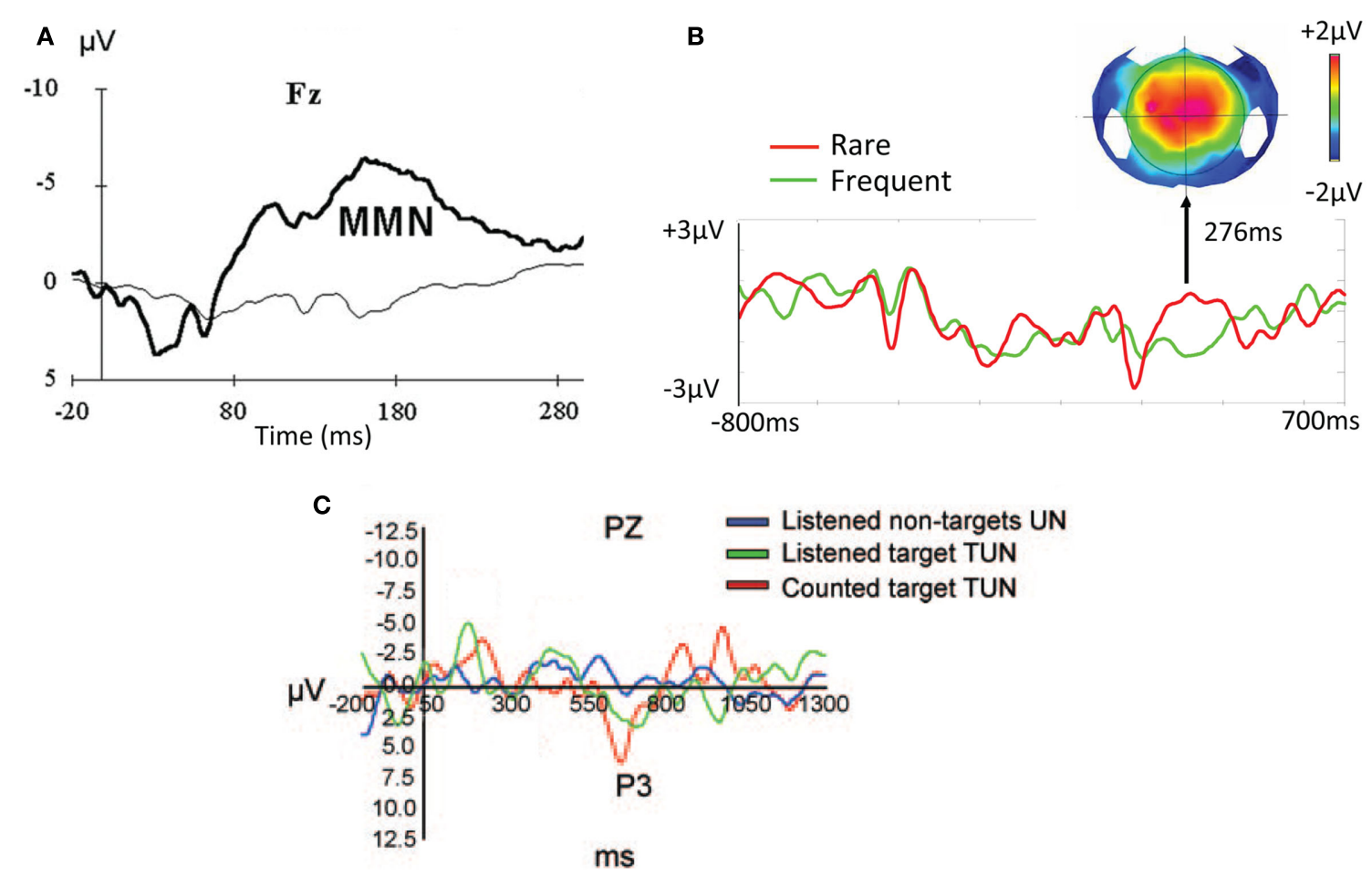

FIGURE 2 | Mismatch negativity (MMN) and P300 in disorders of consciousness. (A) MMN elicited in a VS patient by $247 \mathrm{~Hz}$ deviant tones (10\% probability) relative to $440 \mathrm{~Hz}$ standard tones. Adapted from Kotchoubey et al. (2005). (B) P3a elicited in MCS patient by rare sinusoidal tones (20\% probability). Adapted from Bekinschtein et al. (2009). (C) P3b generated by MCS patient when counting task-relevant, unfamiliar target names presented amongst other unfamiliar names. Adapted from Schnakers et al. (2008). many DoC patients does not inform the question of whether they were aware of the stimuli. Indeed, it is unlikely that most patients were conscious of them, given the severity of their neurological and clinical dysfunction as recorded by behavioral evaluations.

The second, more difficult question raised by these findings in the DoC literature relate to the underlying mechanisms of the positive link between $\mathrm{MMN} / \mathrm{P} 3 \mathrm{a}$ responses and later chances of recovery. Indeed, Wijnen et al. (2007) regularly tracked longitudinal changes in the MMN elicited by VS patients for an average of 3.5 months, and found that its amplitude correlated with progressively improving behavioral indices of recovery. Furthermore, the MMN amplitude reached near-normal levels around the time patients started to show inconsistent command-following, and preceded the observation of behavioral markers indicating a reliable recovery of consciousness. This evidence suggests that, though attention and consciousness are distinct phenomena, the cognitive processes and neural mechanisms of which they are comprised might share much in common. Certainly, networks that subserve attentional processing seem to be able to assist in the rehabilitation of those involved in generating the re-entrant feedback considered to be vital for conscious awareness (Boly et al., 2011a). Although the validity of these results have been debated (Boly et al., 2011b; King et al., 2011), a deeper understanding of these processes would help disambiguate the relationship between attention and awareness, and how they interact at different levels of consciousness.

\section{THE P3b IN DISORDERS OF CONSCIOUSNESS}

Building upon the oddball P300 studies highlighted in the previous section, some recent studies have attempted to explicitly dissociate levels of attentional processing in DoC (Schnakers et al., 2008; Bekinschtein et al., 2009; Faugeras et al., 2011). To do so, they have relied on the consensus that the $\mathrm{P} 3 \mathrm{~b}$ is seen as a marker of task-relevant, conscious processing of auditory information (Polich, 2007). Bekinschtein et al. (2009) and Faugeras et al. (2011) employed a paradigm consisting of series of tone sequences containing a two-level structure of occasional irregularities: shortterm ("local") violations within a five-sound sequence, and longterm ("global") violations of the expectancies of such sequences. Importantly, in control subjects, local violations only evoked early frontal MMN/P3a. In contrast, global violations, which were counterbalanced to be completely independent of psychophysical stimulus properties, were indexed by a later, parietal $\mathrm{P} 3 \mathrm{~b}$, but only when the subject was aware of the long-term structural regularities in the stimuli and was attending to them. Amongst DoC patients, qualitatively similar patterns were observed in some VS (Faugeras et al., 2011) and MCS patients (Bekinschtein et al., 2009). Furthermore, in both studies, the minority of patients who appeared to show an awareness of the global pattern violation also showed positive signs of recovery. These findings suggest that such awareness is strong indication of preserved networks that support the regaining of behaviorally evidenced consciousness. Recently, Faugeras et al. (2012) reported results from a large cohort of DoC patients tested 
with this paradigm. Their findings corroborate the link between the existence of a global effect and behaviorally measurable consciousness (or subsequent recovery thereof), and with evidence of stimulus expectancy and learning effects.

Schnakers et al. (2008) went further and employed an "active" ERP paradigm with DoC patients, where their responses to context-dependent task instructions were measured. Specifically, they compared the P3b elicited across a pair of conditions: one in which patients were asked to passively listen to their own name or a pre-specified target name embedded in a sequence of unfamiliar names, and another in which they were asked to count the occurrence of their own name or pre-specified target names. They found that 9 out of 14 MCS patients generated larger P3b amplitudes when asked to count the target names (their own or unfamiliar) as compared to just listening to them (see Figure 2C). They took this finding to imply that, to some extent, the patients were able to exercise task-selective attentional control to follow the task instructions.

These studies demonstrate that some patients appear to be able to demonstrate the ability to deploy selective attention in a task-contingent manner. This is because, in healthy controls, they explicitly disambiguate P300 responses that could only be attributed to endogenous attentional control and awareness of task-related contingencies, from those that could be generated by differential stimulus probabilities (Polich and Kok, 1995). However, despite this, the question still remains as to whether the same or even something similar can be inferred about patients. More specifically, as highlighted by Overgaard (2009) in the distinction between "reports" and "signals," there is still the unresolved question about the extent to which finding evidence of an endogenous attentional control signal like the $\mathrm{P} 3 \mathrm{~b}$ in a patient can be used to infer the presence of reportable conscious content. Previous research with healthy participants has found striking examples of dissociations between attention and consciousness, showing that these two processes, though often coeval, can indeed be separated under appropriate conditions (Koch and Tsuchiya, 2007; Koivisto et al., 2009). Such subtle dissociations are challenging to measure in patient populations with the passive paradigms discussed here. Addressing such issues with DoC patients might require complementary evidence from active tasks, and perhaps measurements of their metacognitive understanding of stimulus perception. Distinct from, but as important as these theoretical issues, is the clinically relevant question of why, in the significant minority of patients able to deploy endogenous attention, there was a disconnection between their covert cognitive abilities and overt behavioral signs of awareness. As before with the MMN, future research will need to explore in greater depth, how and why such attentional control predicts recovery of consciousness.

\section{THE MMN AND P300 IN SLEEP}

The research into ERPs evoked during various stages of sleep in healthy adults sheds light on how altered states of consciousness affect the attention and awareness of external stimuli (Atienza et al., 2001; Campbell and Colrain, 2002). The consensus often expressed is that there is no evidence for the MMN or the P300 in stage 2 sleep (Loewy et al., 1996, 2000; Cote, 2002; Colrain and Campbell, 2007). K-complexes appear to be the main evoked potentials observed (Bastuji et al., 1995), in addition to delayed evoked potentials that are functionally dissimilar to the MMN/P300 (Nielsen-Bohlman et al., 1991; Van Sweden et al., 1994; Nordby et al., 1996). Evoking an MMN in this sleep stage has required the use of hyper-salient stimuli, involving very rare, extremely deviant stimuli. Similarly evocative stimuli, like the subject's own name, are required to trigger a P300 in stage 2 sleep (Perrin et al., 1999). However, it is worth noting that such responses appear to be non-selective, as they have been observed even for other names and repetitive tones (Bastuji et al., 1995; Perrin et al., 1999, 2000). Furthermore, it has been argued that emotionally charged names might be processed quite differently to neutral words (see Bastuji et al., 2002 for a discussion). Indeed, N400 ERPs can be elicited using semantically incongruent neutral words during stage 2 sleep (Brualla et al., 1998; Perrin et al., 2002), and sentences (Ibáñez et al., 2006), though these too suggest diminished discriminative abilities.

Alongside these findings, studies into the transitions between sleep stages have found that the amplitude of the P300 reduces in sync with arousal levels of participants, and their ability to generate any behavioral responses (Sallinen and Lyytinen, 1997). This fits well with our understanding of the P300 as a reliable marker of indepth, conscious processing of external stimuli. Generally speaking, findings of reductions in amplitudes of late ERPs are keeping in with the notion that falling asleep is marked by a global decrease in long-range thalamo-cortical connectivity occurring in the early stages of the process (Magnin et al., 2010; Goupil and Bekinschtein, 2011; Sämann et al., 2011). There is some recent fMRI evidence suggesting that cortico-cortical connectivity during sleep might remain consistent across sleep stages (Koike et al., 2011), and even increase during light sleep (Spoormaker et al., 2010). However, the implications of these findings for our understanding of the changes in ERPs during sleep remain to be explored.

Event-related potentials elicited during REM sleep present quite a different picture to sleep stage two and deep sleep. Researchers have found significant MMNs (see Figure 3A) to rare, deviant stimuli in REM sleep (Sabri and Campbell, 2005; Sculthorpe et al., 2009). These findings are taken to imply that though finetuned attentional focusing and gating might not be available in REM sleep, covert, pre-attentional monitoring of temporal auditory information is nevertheless functional. However, the greatly reduced acuity of such a monitoring system is reflected in the variability of $\mathrm{MMN}$-related results reported in literature (see Kotchoubey, 2005b for review). Atienza et al. (2002) expressed the general consensus that MMNs are observable in REM sleep, but only under more constrained experimental settings, i.e., very rare deviations in pitch occurring in tone sequences with inter-stimulus intervals less than $1.5 \mathrm{~s}$.

Similarly, P300s to salient stimuli have also been observed in REM sleep (Cote and Campbell, 1999; Cote et al., 2001). Cote et al. (2001) used rare pitch and intensity deviant tones to elicit the equivalent of a P3a in REM sleep (see Figure 3B). Interestingly, they found that when wake subjects were not attending to the tone stimuli, only the hyper-salient (very loud and very rare) deviants elicited a frontal P3a. Similarly, the P3a observed during REM sleep was also elicited only by such strong deviants, and had a similar latency (though it was reduced in amplitude, and did not have 


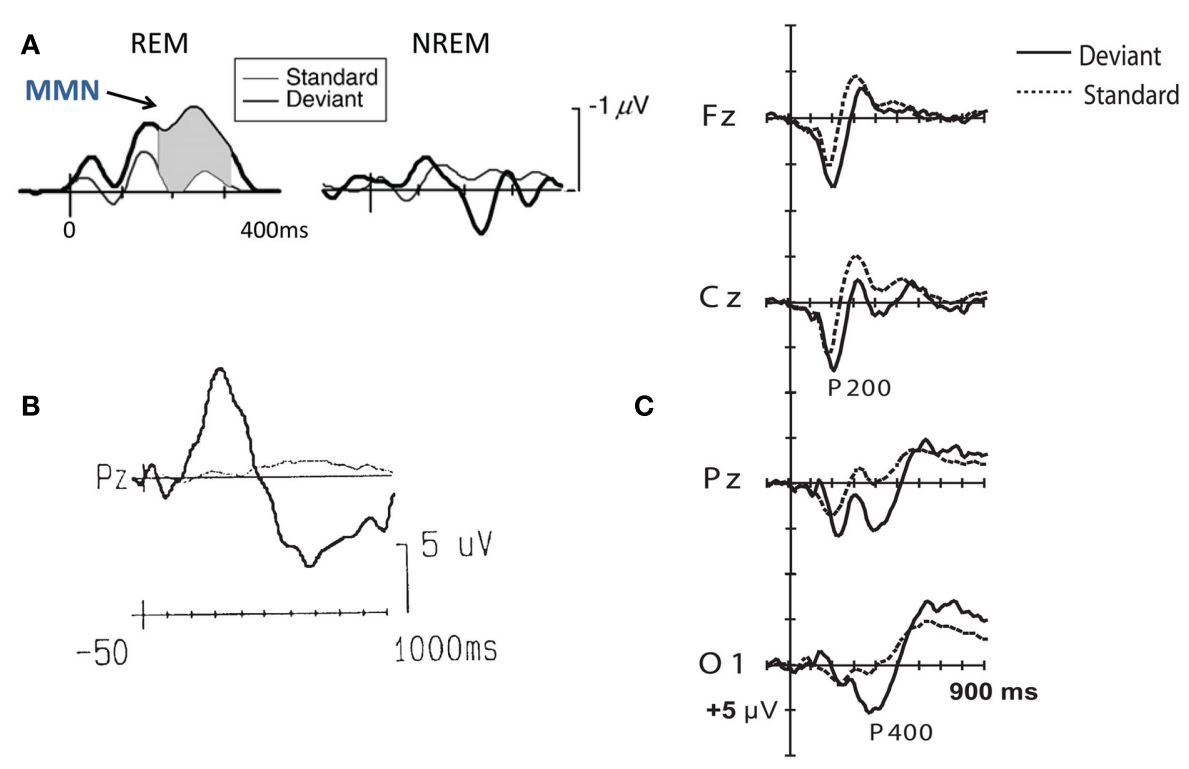

FIGURE 3 | Mismatch negativity (MMN) and P300 in sleep. (A) MMN observed during REM and Non-REM sleep by deviants (6.7\% probability) embedded in alternating tone sequences. Adapted from Sculthorpe et al. (2009). (B) P300 observed during REM sleep by intensity deviants $(5 \%$ probability). Adapted from Cote and Campbell (1999). (C) Occipital P400 observed during tonic REM sleep only in participants instructed to respond to $2000 \mathrm{~Hz}$ deviant tones ( $10 \%$ probability) presented amongst $1000 \mathrm{~Hz}$ standard tones. Adapted from Takahara et al. (2006). the characteristic frontal topography of the waking P3a). Based on this parallel between inattentive wakefulness and REM sleep, the authors suggest that though their subjects might have been able to "consciously" detect the deviants in REM, they were unable to attend to, or perceive them to an extent deep enough to form rich memories or be woken up. In this sense, REM sleep could be an example of an altered state of consciousness displaying a rare disjunction between attention and (semi-)conscious awareness.

In a more recent study, Takahara et al. (2006) modulated endogenous attentional bias in a study employing auditory tone streams with rare frequency deviants played to participants during REM sleep, over two overnight recording conditions. During the "passive" condition, participants were asked to passively listen to the tones, while in the other "active" condition, they were asked to attend to the auditory streams and respond with a finger movement whenever they detected a deviant. The authors found a significantly larger, occipitally focused P400 ERP in the latter condition (see Figure 3C). They interpreted this ERP as a delayed, spatially shifted P3b manifested during REM sleep, which indexed endogenous task-selective attention focused on the deviants. It is worth noting that such P400s were only observed during tonic REM sleep. A similar tonic "REM-P3" has been documented by Sallinen et al. (1996) in response to deviants in a standard oddball study. This finding, if successfully replicated, would be in contrast to findings from previous studies, and suggests that subjects might retain some amount of attentional control even during REM sleep.

\section{THE MMN AND P300 IN ANESTHESIA}

The effect of sedatives on brain dynamics is known to be complex and differentiated (Heinke and Koelsch, 2005). Brain regions are affected in different ways by different anesthetics used in clinical medicine, and also by their dosage levels. But in general, they are thought to affect the brain in a manner that is functionally similar to sleep: by disrupting long-range interactions across key distributed networks that subserve conscious perception (Stamatakis et al., 2010).

Though the literature on ERPs in anesthesia is relatively sparse, many studies of the effect of anesthetics on the MMN have documented a decrease in amplitude. Increasing levels of the anesthetic propofol were associated with decreasing MMN amplitudes elicited by an auditory oddball paradigm (Heinke et al., 2004). At unconsciousness, the MMN was completely abolished. In fact, it has been reported that the MMN is abolished even before the subjective loss of consciousness (see Figure 4A; Simpson et al., 2002). Early measurements of changes in the P300 have also shown a similar pattern. Several studies have documented dramatic dropoffs in P3a amplitudes as subjects were progressively sedated, with complete abolishment at unconsciousness (Plourde and Boylan, 1991; Sneyd et al., 1994; Reinsel et al., 1995).

In the context of this review, studies that have investigated the onset of and recovery from sedation provide interesting insights into the complex influence of anesthetics on the interaction between attention and consciousness. Plourde and Picton (1991) tested patients who were anesthetized for surgery, at different stages: during induction of anesthesia, while in surgical anesthesia, during emergence from sedation, and during recovery from anesthesia. All through, participants were asked to press a button whenever they heard the rare, unpredictable frequency deviant presented within an oddball task. The authors reported finding a significant P300 whenever participants correctly detected a deviant during the first induction and final recovery stages. They point out that during the emergence stage, participants were able to open 


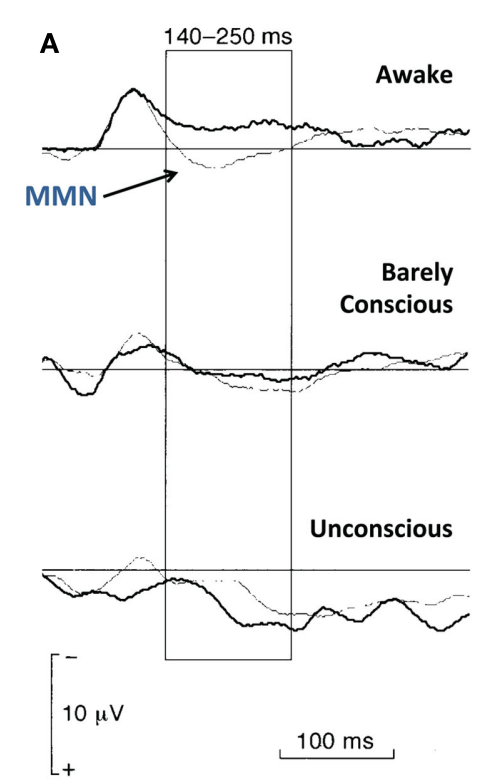

FIGURE 4 | Mismatch negativity (MMN) and P300 in anesthesia. (A) MMN elicited at different levels of consciousness by $25 \mathrm{~ms}$ tones (15\% probability) presented amongst $75 \mathrm{~ms}$ tones. Adapted from Simpson et al.

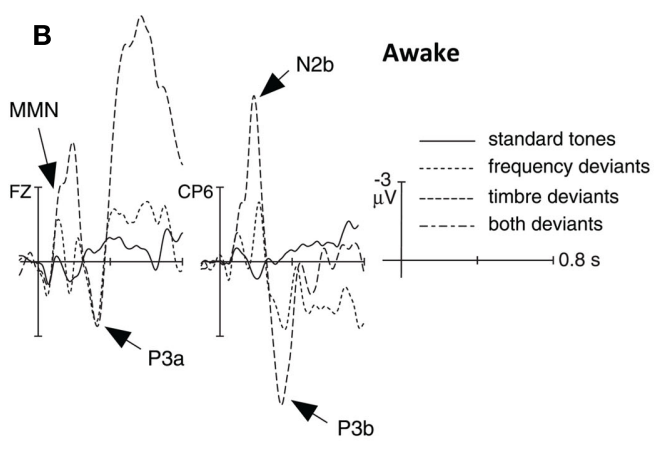

Deep Sedation

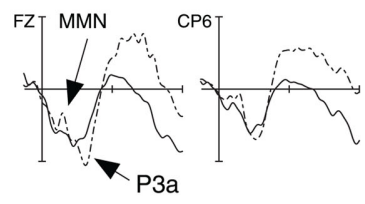

their eyes on command, but did not generate P300s, and in fact, were unable to correctly detect deviants most of the time. This finding has parallels with a more recent study by Koelsch et al. (2006), where participants were first trained to press a button only in response to deviants of timbre, but not frequency in an oddball paradigm, and then induced into a level of "deep sedation" using propofol. In this state of anesthesia - shallower than surgical anesthesia - participants were behaviorally arousable by loud/repeated utterances of their own name, or by mild prodding. The study found that both MMN and P3a ERPs were elicited during deep sedation, though they were attenuated (see Figure 4B). However, the P3b was absent during this period. As participants recovered from sedation, the MMN increased back to normal levels immediately, but neither the P3a nor the P3b were visible. The authors interpret this dissociation to imply that though preattentive auditory sensory mechanisms returned back to normal as soon as participants were able to respond behaviorally, more late-stage attentional and awareness-related processed indexed by the P300 took much longer to recover. As argued by van Hooff et al. (1997), these results support the notion that the effect of anesthesia on cognitive ERPs, including the MMN and the P300 has many similarities to that of stage $2-3$ sleep.

\section{GENERAL DISCUSSION}

In this review, we have attempted to bring together a broad range of findings in the scientific literature that sheds light on the interplay between attention and consciousness by studying the impaired brain in action. These impairments, namely, clinical DoC, natural sleep, and sedation, can be considered as three distinct variations in the levels of consciousness in which cognition can exist. In particular, we suggest that by causally inducing changes between these levels, as in the case of sleep and sedation, we can improve
(2002). (B) P3a observed for task-relevant timbre deviants $16.67 \%$ probability), alongside an absence of P3b during deep sedation. Adapted from Koelsch et al. (2006). our understanding of the profound neurological dysfunction seen in DoC and their impact on attention and consciousness.

Of course, this is not to say that we can draw direct parallels between data or findings from states in sleep or sedation, and states in DoC. For one thing, even within such disorders, loss of consciousness arises due to a range of very different etiologies, including hypoxia, stroke and traumatic brain injury. Patients progress through different paths of recovery, which tend to depend not only on this etiology but also on their age and rehabilitative support they might receive. Hence, when assessing a patient at a particular point in time post-ictus (i.e., after the occurrence of the incident that induced the DoC), it is difficult to make accurate judgments about the nature of their cognitive processes based simply on behavior. As mentioned earlier, a high rate of misdiagnosis has been prevalent, leading to troubling ethical issues for clinical medicine (Schnakers et al., 2009). Though electrophysiology, beginning with measurements of ERPs, has begun to elucidate the nature of cognitive dysfunction in DoC and even produce compelling evidence of awareness in some patients (Cruse et al., 2011a,b; Goldfine et al., 2011), it is still difficult to draw conclusions for diagnosis or prognosis at a single patient level, because of the large number of factors contributing to the variability observed in patient data.

Consequently, any parallels that are highlighted between sleep, sedation, and DoC in this article are qualified with respect to the level of explanation at which they are addressed. Translating such general patterns to inform the diagnosis of patients with their unique histories will depend on ongoing research to delineate both the nature and extent of the individual variability in the findings. Nevertheless, as neuroimaging, and in particular EEG findings from ever larger cohorts of patients accumulate, some broad patterns have emerged more consistently. By linking these patterns 
to findings from research into sleep and anesthesia, we can draw some generalizations about the interplay between attention and consciousness:

1. A considerable amount of pre-attentive and early, bottom-up attentive processing can be accomplished in the brain in the absence of rich, memorable conscious experience. This wellestablished fact, in the current context, is backed up by a wealth of ERP literature from sleep and sedation, and implies that observing similar ERPs in DoC patients does not provide strong evidence either way about the level of their consciousness.

2. Nevertheless, evidence of extant pre-attentive processing in seemingly unconscious patients is predictive of delayed overt behavioral recovery. In addition, the complete lack of any early pre-attentive processing of stimuli is often prognosticative of poor chances of recovery.

3. A significant minority of behaviorally unresponsive patients appear to be able to deploy selective attention to task-relevant stimuli, and generate ERPs suggesting that they might retain some form of awareness. This is complemented by evidence from sleep and sedation: apparently unconscious subjects in stage 2 (and deeper) sleep and in surgical sedation do not show similar ERP signs of awareness (with the exception of REM sleep phases).

4. During sleep and sedation, an interesting dissociation occurs between attention and consciousness. During deep (but not complete) sedation, some pre-attentive processing and bottomup attentional orienting is spared. In contrast, task-selective endogenous processing seems to be abolished not only during sedation, but also during the recovery phase, where the subjects consciously respond to stimuli but produce no P300s. This is in contrast to REM sleep, where such processing seems to be diminished but functional.

\section{REFERENCES}

Alain, C., and Woods, D. L. (1997). Attention modulates auditory pattern memory as indexed by eventrelated brain potentials. Psychophysiology 34, 534-546.

Alain, C., Woods, D. L., and Ogawa, K. H. (1994). Brain indices of automatic pattern processing. Neuroreport 6, 140-144.

Atienza, M., Cantero, J., and Escera, C. (2001). Auditory information processing during human sleep as revealed by event-related brain potentials. Clin. Neurophysiol. 112, 2031-2045.

Atienza, M., Cantero, J. L., and Dominguez-Marin, E. (2002). Mismatch negativity (MMN): an objective measure of sensory memory and long-lasting memories during sleep. Int. J. Psychophysiol. 46, 215-225.

Bastuji, H., García-Larrea, L., Franc, C., and Mauguière, F. (1995). Brain processing of stimulus deviance during slow-wave and paradoxical sleep: a study of human auditory evoked responses using the oddball paradigm. J. Clin. Neurophysiol. 12, 155-167.

Bastuji, H., Perrin, F., and Garcia-Larrea, L. (2002). Semantic analysis of auditory input during sleep: studies with event related potentials. Int. J. Psychophysiol. 46, 243-255.

Bekinschtein, T. A., Dehaene, S., Rohaut, B., Tadel, F., Cohen, L., and Naccache, L. (2009). Neural signature of the conscious processing of auditory regularities. Proc. Natl. Acad. Sci. U.S.A. 106, 1672-1677.

Boly, M., Garrido, M. I., Gosseries, O., Bruno, M.-A., Boveroux, P., Schnakers, C., Massimini, M., Litvak, V., Laureys, S., and Friston, K. (2011a). Preserved feedforward but impaired top-down processes in the vegetative state. Science 332, 858-862.

Boly, M., Garrido, M. I., Gosseries, O., Bruno, M.-A., Boveroux, P.,

5. Many patients in DoC show ERP signs of being in intermediate stages of cognition involving partial and temporally fluctuating dissociations between pre-attentive, post-attentive processes and conscious experience. Though they might be physically arousable, and be able to attend to certain stimuli, they might not have detailed spatial, temporal or self consciousness. Though this is currently speculative, behaviorally and in terms of their ERPs, DoC patients could be thought of as being in cognitive states similar to REM sleep or intermediate sedation. However, this comparison is currently very limited in its detail, and should be qualified in terms of the level of abstraction at which it is valid.

\section{CONCLUSION}

In this article, we have aimed to bring together the relevant ERP literature on altered states of consciousness, including DoC, sleep and sedation, which speak to questions about the interplay between auditory attention and consciousness. The findings presented here have highlighted examples of unique disconnections between these often tightly intertwined processes, providing valuable insights into the underlying nature of the behavioral states these disengagements can produce. In particular, we have focused on question of how parallels between findings from studies into sleep and sedation can inform our understanding about cognitive processing and the nature of conscious experience in DoC, while emphasizing the divergences that warrant further study.

\section{ACKNOWLEDGMENTS}

This research was supported by generous funding from the Medical Research Council (U.1055.01.002.00001.01), the James S. McDonnell Foundation, and the Wellcome Trust Biomedical Research Fellowship awarded to Tristan A. Bekinschtein.

Schnakers, C., Massimini, M., Litvak, V., Laureys, S., and Friston, K. (2011b). Response to comment on "preserved feedforward but impaired top-down processes in the vegetative state." Science 334, 1203.

Brualla, J., Romero, M. F., Serrano, M. and Valdizán, J. (1998). Auditory event-related potentials to semantic priming during sleep. Electroencephalogr. Clin. Neurophysiol. 108, 283-290.

Campbell, K. B., and Colrain, I. M. (2002). Event-related potential measures of the inhibition of information processing: II. The sleep onset period. Int. J. Psychophysiol.46, 197-214.

Cavinato, M., Volpato, C., Silvoni, S., Sacchetto, M., Merico, A., and Piccione, F. (2011). Event-related brain potential modulation in patients with severe brain damage. Clin. Neurophysiol. 122, 719-724.

Colrain, I. M., and Campbell, K. B. (2007). The use of evoked potentials in sleep research. Sleep Med. Rev. 11, 277-293.

Comerchero, M. D., and Polich, J. (1999). P3a and P3b from typical auditory and visual stimuli. Clin. Neurophysiol. 110, 24-30.

Cote, K. A. (2002). Probing awareness during sleep with the auditory odd-ball paradigm. Int. J. Psychophysiol. 46, 227-241.

Cote, K. A., and Campbell, K. B. (1999). P300 to high intensity stimuli during REM sleep. Clin. Neurophysiol. 110, 1345-1350.

Cote, K. A., Etienne, L., and Campbell, K. B. (2001). Neurophysiological evidence for the detection of external stimuli during sleep. Sleep 24, 791-803.

Courchesne, E., Hillyard, S. A., and Galambos, R. (1975). Stimulus novelty, task relevance and the visual evoked potential in man. Electroencephalogr. Clin. Neurophysiol. 39, 131-143. 
Cruse, D., Chennu, S., Chatelle, C., Bekinschtein, T. A., FernándezEspejo, D., Pickard, J. D., Laureys, S., and Owen, A. M. (2011a). Bedside detection of awareness in the vegetative state: a cohort study. The Lancet 378, 2088-2094.

Cruse, D., Chennu, S., Chatelle, C., Fernández-Espejo, D., Bekinschtein, T. A., Pickard, J. D., Laureys, S., and Owen, A. M. (2011b). The relationship between aetiology and covert cognition in the minimallyconscious state. Neurology (in press).

Daltrozzo, J., Wioland, N., Mutschler, V., and Kotchoubey, B. (2007). Predicting coma and other low responsive patients outcome using eventrelated brain potentials: a metaanalysis. Clin. Neurophysiol. 118, 606-614.

Donchin, E. (1981). Surprise!... Surprise? Psychophysiology 18, 493-513.

Donchin, E., and Coles, M. G. H. (1988). Is the P300 component a manifestation of context updating? Behav. Brain Sci. 11, 357-374.

Duncan, C. C., Barry, R. J., Connolly, J. F., Fischer, C., Michie, P. T., Näätänen, R., Polich, J., Reinvang, I., and Van Petten, C. (2009). Eventrelated potentials in clinical research: guidelines for eliciting, recording, and quantifying mismatch negativity, P300, and N400. Clin. Neurophysiol. 120, 1883-1908.

Escera, C., Yago, E., and Alho, K. (2001). Electrical responses reveal the temporal dynamics of brain events during involuntary attention switching. Eur. J. Neurosci. 14, 877-883.

Faugeras, F., Rohaut, B., Weiss, N., Bekinschtein, T., Galanaud, D., Puybasset, L., Bolgert, F., Sergent, C., Cohen, L., Dehaene, S., and Naccache, L. (2012). Event related potentials elicited by violations of auditory regularities in patients with impaired consciousness. Neuropsychologia 50, 403-418.

Faugeras, F., Rohaut, B., Weiss, N., Bekinschtein, T. A., Galanaud, D., Puybasset, L., Bolgert, F., Sergent, C., Cohen, L., Dehaene, S., and Naccache, L. (2011). Probing consciousness with event-related potentials in the vegetative state. Neurology (in press).

Fischer, C., Luaute, J., and Morlet, D. (2010). Event-related potentials (MMN and novelty P3) in permanent vegetative or minimally conscious states. Clin. Neurophysiol. 121, 1032-1042.

Garrido, M. I., Kilner, J. M., Kiebel, S. J., and Friston, K. J. (2007). Evoked brain responses are generated by feedback loops. Proc. Natl. Acad. Sci. U.S.A. 104, 20961-20966.

Garrido, M. I., Kilner, J. M., Kiebel, S. J., and Friston, K. J. (2009). Dynamic causal modeling of the response to frequency deviants. J. Neurophysiol. 101, 2620-2631.

Goldfine, A. M., Victor, J. D., Conte, M. M., Bardin, J. C., and Schiff, N. D. (2011). Determination of awareness in patients with severe brain injury using EEG power spectral analysis. Clin. Neurophysiol. 122, 2157-2168.

Goupil, L., and Bekinschtein, T. A. (2011). Cognitive processing during the transition to sleep. Arch. Ital. Biol. (in press).

Heinke, W., Kenntner, R., Gunter, T. C., Sammler, D., Olthoff, D., and Koetsch, S. (2004). Sequential effects of increasing propofol sedation on frontal and temporal cortices as indexed by auditory event-related potentials. Music Ther. Today 3, 617-625.

Heinke, W., and Koelsch, S. (2005). The effects of anesthetics on brain activity and cognitive function. Curr. Opin. Anesthesiol. 18, 625-631.

Ibáñez, A., López, V., and Cornejo, C. (2006). ERPs and contextual semantic discrimination: degrees of congruence in wakefulness and sleep. Brain Lang. 98, 264-275.

Jones, S. J., Vaz Pato, M., Sprague, L., Stokes, M., Munday, R., and Haque, N. (2000). Auditory evoked potentials to spectro-temporal modulation of complex tones in normal subjects and patients with severe brain injury. Brain 123, 1007-1016.

King, J.-R., Bekinschtein, T. A., and Dehaene, S. (2011). Feedforward versus top-down processing in the vegetative state: inconclusive evidence. Science 334, 1203.

Koch, C., and Tsuchiya, N. (2007). Attention and consciousness: two distinct brain processes. Trends Cogn. Sci. (Regul. Ed.) 11, 16-22.

Koelsch, S., Heinke, W., Sammler, D., and Olthoff, D. (2006). Auditory processing during deep propofol sedation and recovery from unconsciousness. Clin. Neurophysiol. 117, 1746-1759.

Koike, T., Kan, S., Misaki, M., and Miyauchi, S. (2011). Connectivity pattern changes in defaultmode network with deep non-REM and REM sleep. Neurosci. Res. 69, 322-330.

Koivisto, M., Kainulainen, P., and Revonsuo, A. (2009). The relationship between awareness and attention: evidence from ERP responses. Neuropsychologia 47, 2891-2899.
Kok, A. (2001). On the utility of P3 amplitude as a measure of processing capacity. Psychophysiology 38, 557-577.

Kotchoubey, B. (2005a). Apallic syndrome is not apallic: is vegetative state vegetative? Neuropsychol. Rehabil. 15, 333-356.

Kotchoubey, B. (2005b). Event-related potential measures of consciousness: two equations with three unknowns. 150, 427-444.

Kotchoubey, B., Lang, S., Baales, R., Herb, E., Maurer, P., Mezger, G. Schmalohr, D., Bostanov, V., and Birbaumer, N. (2001). Brain potentials in human patients with extremely severe diffuse brain damage. $\mathrm{Neu}$ rosci. Lett. 301, 37-40.

Kotchoubey, B., Lang, S., Mezger, G. Schmalohr, D., Schneck, M., Semmler, A., Bostanov, V., and Birbaumer, N. (2005). Information processing in severe disorders of consciousness: vegetative state and minimally conscious state. Clin. Neurophysiol. 116, 2441-2453.

Lew, H. L., Dikmen, S., Slimp, J., Temkin, N., Lee, E. H., Newell, D., and Robinson, L. R. (2003). Use of somatosensory-evoked potentials and cognitive event-related potentials in predicting outcomes of patients with severe traumatic brain injury. Am. J. Phys. Med. Rehabil. 82, 53-61.

Lew, H. L., Slimp, J., Price, R., Massagli, T. L., and Robinson, L. R. (1999). Comparison of speech-evoked vs. tone-evoked P300 response: implications for predicting outcomes in patients with traumatic brain injury. Am. J. Phys. Med. Rehabil. 78, 367-371.

Loewy, D. H., Campbell, K. B., and Bastien, C. (1996). The mismatch negativity to frequency deviant stimuli during natural sleep. Electroencephalogr. Clin. Neurophysiol. 98, 493 -501 .

Loewy, D. H., Campbell, K. B., de Lugt, D. R., Elton, M., and Kok, A. (2000) The mismatch negativity during natural sleep: intensity deviants. Clin. Neurophysiol. 111, 863-872.

Magnin, M., Rey, M., Bastuji, H., Guillemant, P., Mauguière, F., and GarciaLarrea, L. (2010). Thalamic deactivation at sleep onset precedes that of the cerebral cortex in humans. Proc. Natl. Acad. Sci. U.S.A. (in press).

Marosi, M., Prevec, T., Masala, C., Bramanti, M., Giorganni, R., Luef, G. Berek, K., and Saltuari, L. (1993). Event-related potentials in vegetative state. Lancet 341, 1473.

Müller, B. W., Achenbach, C., Oades, R. D., Bender, S., and Schall, U. (2002).
Modulation of mismatch negativity by stimulus deviance and modality of attention. Neuroreport 13, 1317-1320.

Muller-Gass, A., Macdonald, M., Schröger, E., Sculthorpe, L., and Campbell, K. (2007). Evidence for the auditory P3a reflecting an automatic process: elicitation during highly-focused continuous visual attention. Brain Res. 1170, 71-78.

Näätänen, R. (1990). The role of attention in auditory information processing as revealed by event-related potentials and other brain measures of cognitive function. Behav. Brain Sci. 13, 201-288.

Näätänen, R. (1992). Attention and Brain Function. Hillsdale: L. Erlbaum Associates.

Näätänen, R., Gaillard, A. W. K., and Mäntysalo, S. (1978). Early selectiveattention effect on evoked potential reinterpreted. Acta Psychol. (Amst.) 42, 313-329.

Näätänen, R., and Michie, P. T. (1979). Early selective-attention effects on the evoked potential: a critical review and reinterpretation. Biol. Psychol. 8 , 81-136.

Näätanen, R., Paavilainen, P., Rinne, T., and Alho, K. (2007). The mismatch negativity (MMN) in basic research of central auditory processing: a review. Clin. Neurophysiol. 118, 2544-2590.

Nielsen-Bohlman, L., Knight, R. T., Woods, D. L., and Woodward, K. (1991). Differential auditory processing continues during sleep. Electroencephalogr. Clin. Neurophysiol. 79, 281-290.

Nordby, H., Hugdahl, K., Stickgold, R., Bronnick, K. S., and Hobson, J. A. (1996). Event-related potentials (ERPs) to deviant auditory stimuli during sleep and waking. Neuroreport 7, 1082-1086.

Overgaard, M. (2009). "How can we know if patients in coma, vegetative state or minimally conscious state are conscious?" in Coma Science: Clinical and Ethical Implications, Vol. 177 of Progress in Brain Research, eds S. Laureys, N. D. Schiff, and A. M. Owen (Elsevier), 1771117719.

Perrin, F., Bastuji, H., and Garcia-Larrea, L. (2002). Detection of verbal discordances during sleep. Neuroreport 13, 1345-1349.

Perrin, F., Bastuji, H., Mauguière, F., and García-Larrea, L. (2000). Functional dissociation of the early and late portions of human K-complexes. $\mathrm{Neu}$ roreport 11, 1637-1640.

Perrin, F., Garci'a-Larrea, L., Mauguière, F., and Bastuji, H. (1999) 
A differential brain response to the subject's own name persists during sleep. Clin. Neurophysiol. 110, 2153-2164.

Perrin, F., Schnakers, C., Schabus, M., Degueldre, C., Goldman, S., Bredart, S., Faymonville, M.-E., Lamy, M., Moonen, G., Luxen, A., Maquet, P., and Laureys, S. (2006). Brain response to one's own name in vegetative state, minimally conscious state, and locked-in syndrome. Arch. Neurol. 63, 562-569.

Plourde, G., and Boylan, J. F. (1991). The long-latency auditory evoked potential as a measure of the level of consciousness during sufentanil anesthesia. J. Cardiothorac. Vasc. Anesth. 5, 577-583.

Plourde, G., and Picton, T. W. (1991). Long-latency auditory evoked potentials during general anesthesia. Anesth. Analg. 72, 342-350.

Polich, J. (2004). Clinical application of the P300 event-related brain potential. Phys. Med. Rehabil. Clin. N. Am. $15,133-161$.

Polich, J. (2007). Updating P300: an integrative theory of $\mathrm{P} 3 \mathrm{a}$ and $\mathrm{P} 3 \mathrm{~b}$. Clin. Neurophysiol. 118, 2128-2148.

Polich, J., and Criado, J. R. (2006). Neuropsychology and neuropharmacology of P3a and P3b. Int. J. Psychophysiol. 60, 172-185.

Polich, J., and Herbst, K. L. (2000). P300 as a clinical assay: rationale, evaluation, and findings. Int. J. Psychophysiol. 38, 3-19.

Polich, J., and Kok, A. (1995). Cognitive and biological determinants of P300: an integrative review. Biol. Psychol. 41, 103-146.

Qin, P., Di, H., Yan, X., Yu, S., Yu, D., Laureys, S., and Weng, X. (2008). Mismatch negativity to the patient's own name in chronic disorders of consciousness. Neurosci. Lett. 448, 24-28.

Ranganath, C., and Rainer, G. (2003). Neural mechanisms for detecting and remembering novel events. Nat. Rev. Neurosci. 4, 193-202.

Rappaport, M., McCandless, K. L., Pond, W., and Krafft, M. C. (1991). Passive P300 response in traumatic brain injury patients. $J$. Neuropsychiatry Clin. Neurosci. 3, 180-185.

Reinsel, R. A., Veselis, R. A., Wronski, M., and Marino, P. (1995). The
P300 event-related potential during propofol sedation: a possible marker for amnesia? Br. J. Anaesth. 74, 674-680.

Sabri, M., and Campbell, K. B. (2005). Is the failure to detect stimulus deviance during sleep due to a rapid fading of sensory memory or a degradation of stimulus encoding? J. Sleep Res. 14, 113-122.

Sallinen, M., Kaartinen, J., and Lyytinen, H. (1996). Processing of auditory stimuli during tonic and phasic periods of REM sleep as revealed by event-related brain potentials. $J$. Sleep Res. 5, 220-228.

Sallinen, M., and Lyytinen, H. (1997). Mismatch negativity during objective and subjective sleepiness. Psychophysiology 34, 694-702.

Sämann, P. G., Wehrle, R., Hoehn, D., Spoormaker, V. I., Peters, H., Tully, C., Holsboer, F., and Czisch, M. (2011). Development of the brain's default mode network from wakefulness to slow wave sleep. Cereb. Cortex 21, 2082-2093.

Sams, M., Paavilainen, P., Alho, K., and Näätänen, R. (1985). Auditory frequency discrimination and event-related potentials. Electroencephalogr. Clin. Neurophysiol. 62, 437-448.

Schnakers, C., Perrin, F., Schabus, M., Majerus, S., Ledoux, D., Damas, P., Boly, M., Vanhaudenhuyse, A., Bruno, M. A., Moonen, G., and Laureys, S. (2008). Voluntary brain processing in disorders of consciousness. Neurology 71, 1614-1620.

Schnakers, C., Vanhaudenhuyse, A., Giacino, J., Ventura, M., Boly, M., Majerus, S., Moonen, G., and Laureys, S. (2009). Diagnostic accuracy of the vegetative and minimally conscious state: clinical consensus versus standardized neurobehavioral assessment. BMC Neurol. 9 , 35. doi:10.1186/1471-2377-9-35

Schröger, E. (1996). A neural mechanism for involuntary attention shifts to changes in auditory stimulation. J. Cogn. Neurosci. 8, 527-539.

Sculthorpe, L. D., Ouellet, D. R., and Campbell, K. B. (2009). MMN elicitation during natural sleep to violations of an auditory pattern. Brain Res. 1290, 52-62.

Simpson, T. P., Manara, A. R., Kane, N. M., Barton, R. L., Rowlands, C. A., and Butler, S. R. (2002). Effect of propofol anaesthesia on the eventrelated potential mismatch negativity and the auditory-evoked potential N1. Br. J. Anaesth. 89, 382-388.

Sneyd, J. R., Samra, S. K., Davidson, B., Kishimoto, T., Kadoya, C., and Domino, E. F. (1994). Electrophysiologic effects of propofol sedation. Anesth. Analg. 79, 1151-1158.

Spoormaker, V. I., Schröter, M. S., Gleiser, P. M., Andrade, K. C. Dresler, M., Wehrle, R., Sämann, P. G., and Czisch, M. (2010). Development of a large-scale functional brain network during human nonrapid eye movement sleep. $\mathrm{J}$. Neurosci. 30, 11379-11387.

Squires, N. K., Squires, K. C., and Hillyard, S. A. (1975). Two varieties of long-latency positive waves evoked by unpredictable auditory stimuli in man. Electroencephalogr. Clin. Neurophysiol. 38, 387-401.

Stamatakis, E. A., Adapa, R. M., Absalom, A. R., and Menon, D. K. (2010). Changes in resting neural connectivity during propofol sedation. PLoS ONE 5, e14224. doi:10.1371/journal.pone.0014224

Sussman, E., and Winkler, I. (2001). Dynamic sensory updating in the auditory system. Brain Res. Cogn. Brain Res. 12, 431-439.

Sutton, S., Braren, M., Zubin, J., and John, E. R. (1965). Evoked-potential correlates of stimulus uncertainty. Science 150, 1187-1188.

Sutton, S., Tueting, P., Zubin, J., and John, E. R. (1967). Information delivery and the sensory evoked potential. Science 155, 1436-1439.

Takahara, M., Nittono, H., and Hori, T. (2006). Effect of voluntary attention on auditory processing during REM sleep. Sleep 29, 975-982.

van Hooff, J. C., de Beer, N. A M., Brunia, C. H. M., Cluitmans, P. J. M., and Korsten, H. H. M. (1997). Event-related potential measures of information processing during general anesthesia. Electroencephalogr. Clin. Neurophysiol. 103 268-281.

Van Sweden, B., Van Dijk, J. G., and Caekebeke, J. F. V. (1994). Auditory information processing in sleep: late cortical potentials in an oddball paradigm. Neuropsychobiology $29,152-156$.
Verleger, R. (1988). Event-related potentials and cognition: a critique of the context updating hypothesis and an alternative interpretation of P3. Behav. Brain Sci. 11, 343-427.

Wijnen, V. J. M., van Boxtel, G. J. M., Eilander, H. J., and de Gelder, B. (2007). Mismatch negativity predicts recovery from the vegetative state. Clin. Neurophysiol. 118, 597-605.

Winkler, I., Karmos, G., and Näätänen, R. (1996). Adaptive modeling of the unattended acoustic environment reflected in the mismatch negativity event-related potential. Brain Res. 742, 239-252.

Witzke, W., and Schönle, P. W. (1996). Ereigniskorrelierte Potentiale als diagnostisches Mittel in der neurologischen Frührehabilitation. Neurol. Rehabil. 2, 68-80.

Woldorff, M. G., Hillyard, S. A., Gallen, C. C., Hampson, S. R., and Bloom, F. E. (1998). Magnetoencephalographic recordings demonstrate attentional modulation of mismatch-related neural activity in human auditory cortex. Psychophysiology 35, 283-292.

Conflict of Interest Statement: The authors declare that the research was conducted in the absence of any commercial or financial relationships that could be construed as a potential conflict of interest.

Received: 14 October 2011; paper pending published: 12 November 2011; accepted: 18 February 2012; published online: 05 March 2012.

Citation: Chennu S and Bekinschtein TA (2012) Arousal modulates auditory attention and awareness: insights from sleep, sedation, and disorders of consciousness. Front. Psychology 3:65. doi: 10.3389/fpsyg.2012.00065

This article was submitted to Frontiers in Consciousness Research, a specialty of Frontiers in Psychology.

Copyright (-) 2012 Chennu and Bekinschtein. This is an open-access article distributed under the terms of the Creative Commons Attribution Non Commercial License, which permits noncommercial use, distribution, and reproduction in other forums, provided the original authors and source are credited. 